\title{
To compare the safety and efficacy of diacerein and oxaceprol in the management of grade I \& II osteoarthritis of knee
}

\author{
Satyendra Sharad ${ }^{1}$, Dinesh Kansal ${ }^{2, *}$, Vipin Sharma ${ }^{3}$, Parveen Sharma ${ }^{4}$ \\ ${ }^{1}$ Junior Resident, ${ }^{2,4}$ Professor and HOD, ${ }^{3}$ Professor, ${ }^{\mathbf{1 , 2 , 4}}$ Dept. of Pharmacology, ${ }^{\mathbf{3}}$ Dept. of Orthopedics, ${ }^{\mathbf{1 , 2 , 3}}$ Dr. Rajendra Prasad \\ Government Medical College, Kangra, Himachal Pradesh, ${ }^{4}$ Shri Lal Bahadur Shastri Government Medical College \& Hospital, \\ Mandi, Himachal Pradesh, India
}

*Corresponding Author:

Email: dinesh.kansal56@gmail.com

\begin{abstract}
Introduction: Diacerein and oxaceprol are frequently used for the treatment of Grade-I \& II osteoarthritis of knees. Diacerein acts by blocking the action of interleukin-1 whereas oxaceprol prevents leukocyte infiltration in the synovial joints. Both the drugs are effective. But there are few comparative studies regarding safety and efficacy of these two drugs. Hence we planned this study.

Materials and Methods: An open label randomized comparative study was conducted by the departments of Pharmacology and Orthopedics at Dr RPGMC, Tanda, H.P, after taking permission from the IEC. Patients were diagnosed clinically as per American College of Rheumatology (ACR) guidelines and graded radiologically as Grade I \& II osteoarthritis of the knee joint based on Kellgren and Lawrence classification. Then considering exclusion criteria, patients were enrolled after taking written informed consent. 31 and 29 patients were enrolled in diacerein and oxaceprol groups respectively. Tab diacerein $50 \mathrm{mg}$ and oxaceprol $200 \mathrm{mg}$ were prescribed twice daily for three months in respective groups. One patient dropped out in each group, who opted for operative intervention after a few days of enrolment. Efficacy was assessed clinically by WOMAC scale during their follow up at three months. Safety was evaluated clinically considering adverse effects and by complete haemogram \& blood biochemistry.

Results: In diacerein-group, WOMAC score (mean \pm S.D.) improved from 48.77 \pm 18.17 to $29.40 \pm 19.94$ (p-value $=0.00001)$ and in oxaceprol group from $42.59 \pm 19.49$ to $26.58 \pm 16.83$ (p-value $=0.00001$ ). No adverse effect was reported in any group.

Conclusion: Both medicines are almost similar in safety and efficacy.
\end{abstract}

Key words: Diacerein, Oxaceprol, Osteoarthritis of knee.

\section{Introduction}

Osteoarthritis (OA) is a common degenerative joint disorder, characterized by loss of articular cartilage, typically presents with pain and stiffness in the joints. Pain is experienced particularly after prolonged activity and weight bearing; whereas stiffness is experienced after inactivity. It commonly affects the joints of spine and large weight-bearing joints, such as hips and knees. It is the most common joint disease and is the most common cause of locomotor disability in the elderly. Its prevalence in India is $22 \%$ to $39 \%$. Contrary to the popular belief, osteoarthritis is not an inevitable consequence of aging; instead, aging increases the risk of osteoarthritis and advanced osteoarthritis may also occur in many young people in early 20 's. ${ }^{1}$

The exact incidence and prevalence of osteoarthritis is difficult to determine because the clinical syndrome of osteoarthritis (joint pain and stiffness) does not always correspond with the structural changes of osteoarthritis. ${ }^{2}$ It differs in different racial and ethnic groups. Both radiographic hip and hand osteoarthritis were much less frequent among Chinese in the Beijing Osteoarthritis Study than in whites in the Framingham Study. Geographical variation in osteoarthritis epidemiology also exists. Studies from China, which used similar methods and definitions to the Framingham Study, found that the prevalence of bilateral knee osteoarthritis and lateral compartment disease were two to three times higher in Chinese cohorts compared with estimates from the Framingham Osteoarthritis Study. ${ }^{3}$

There are various treatment modalities and oxaceprol and diacerein are being used for a long time. Oxaceprol (N-acetyl-L-hydroxyproline), is an amino acid derivative and acts like analgesic and antiinflammatory, which has been used for decades for the symptomatic treatment of degenerative and inflammatory joint disease in Europe. Its antiinflammatory and analgesic efficacy is comparable to the conventional non-steroidal anti-inflammatory drugs (NSAIDs) like diclofenac, but has a different mode of action. Instead of inhibiting the synthesis of prostaglandins, oxaceprol prevents leukocyte infiltration into the joints, thus inhibiting an early step of inflammatory cascade and presenting a novel class of anti-inflammatory agents. ${ }^{4}$ It is better tolerated than diclofenac. ${ }^{5}$ Oxaceprol has an effect on the microcirculation. It reduces leukocyte adherence in vivo and leukocyte infiltration in mouse in Antigeninduced Arthritis, indicating an effect on synovial microcirculation. ${ }^{6}$

Diacerein is an anthraquinone derivative and works by blocking the actions of interleukin- 1 beta, a protein involved in the inflammation and destruction of cartilage that play a role in the development of symptoms of degenerative joint diseases such as 
osteoarthritis. $^{7}$ The most common side effects of diacerein treatment are diarrhea and discoloration of urine (yellow or pink). Discoloration of urine is due to the elimination of metabolites via the urine and no clinical significance has been found; It may also be dependent on fluid intake. Because there is paucity of comparative studies of their safety and efficacy, we planned this study.

\section{Materials and Methods}

It was a Prospective, Open label, Randomized comparative study and was conducted in the departments of Pharmacology and Orthopedics at Dr. Rajendra Prasad Government Medical College, Kangra at Tanda, Himachal Pradesh after taking permission from Institutional Ethics Committee and Protocol Review Committee-No.- HFW-H-DRPGMC/Ethics/ 2016 Protocol no.74/2016 dated: 04/08/2016.

Patients were screened in the orthopedics OPD. Diagnosis of the osteoarthritis of knee was made clinically based on guidelines laid down by American College of Rheumatology (ACR $)^{8}$ and Grading of severity was done radiologically as per Kellgren and Lawrence classification (K-L classification). ${ }^{9}$

\section{Inclusion Criteria}

1. Clinically diagnosed case of OA knee as per ACR guidelines,

2. Radiologically graded as grade I \& II OA of knee as per $\mathrm{K}-\mathrm{L}$ classification,

3. All age and sex.

\section{Exclusion Criteria}

1. Patients with co-morbidity- physical or psychological,

2. Grade III and IV OA of knee (K-L classification),

3. History of intra articular injections of cortisone,

4. Secondary Osteoarthritis following sepsis or trauma,

5. Patients with lower extremity deformity or sensory loss in the lower limb,

6. Patients with co-existing Rheumatoid arthritis or gout,

7. History of knee joint surgery.

After screening, diagnosing, grading and taking written informed consent 60, patients were enrolled from August 2016 to July 2017. Detailed clinical history and physical examination findings were recorded on the patient's Performa. Severity of patient's problems was assessed on WOMAC scale.

Patients were distributed in two groups as per lottery based randomization chart.

Group 1, consisting of 29 patients, was given tablet oxaceprol $200 \mathrm{mg}$ twice daily for 3 months, whereas Group 2, consisting of 31 patients, was given tablet diacerein $50 \mathrm{mg}$ twice daily for 3 months. 1 patient in each group lost to follow up.

Assessment of Efficacy: The efficacy was assessed on the basis of the Western Ontario and McMaster Universities Arthritis Index (WOMAC) ${ }^{10}$ score by comparing the baseline scores with those at the end of the study period.

Assessment of Safety: Safety assessment was done based on patient's complaint of adverse effects and comparing hematological and biochemical investigations- baseline with after three months.

Investigations: Complete Blood Counts, Random Blood Sugar, Renal Function Test, Liver Function Test, and Lipid Profile were done at the time of enrollment (baseline) and repeated at the completion of treatment and in between if required.

Follow Up: Each patient was called for follow up after 3 months from the date of commencement of the treatment. In between, information about adverse effects was gathered and patient's compliance was ensured by contacting them telephonically once in first seven days and then monthly up to 3 months.

\section{Statistical Analysis}

At the end of study, the data was uploaded on the Microsoft Excel 2007 version. Mean \pm S.D. was calculated. Intra-group and inter-group comparisons were done using paired and unpaired t-tests.

\section{Results}

General Demographic Profile: The patients were from 32 to 80 years of age with mean \pm S.D. $=54.43 \pm 11.93$ years. $90 \%$ patients were females and most of them had bilateral involvement of grade I Osteoarthritis of knees.

Table 1: Baseline parameters of patients

\begin{tabular}{|c|c|c|c|}
\hline Parameters & $\begin{array}{c}\text { Oxaceprol group }(n=28) \\
(\text { Mean } \pm \text { S.D })\end{array}$ & $\begin{array}{l}\text { Diacerein group }(n=30) \\
(\text { Mean } \pm \text { S.D })\end{array}$ & $\begin{array}{c}\text { p-value } \\
\text { (Unpaired t-test) }\end{array}$ \\
\hline Age in years & $53.35 \pm 13.01$ & $55.43 \pm 10.97$ & 0.5121 \\
\hline Female : male ratio & $23: 5$ & $29: 1$ & \\
\hline Pulse (per min) & $76.78 \pm 8.5$ & $79.66 \pm 7.48$ & 0.1755 \\
\hline Systolic BP (mm Hg) & $129.35 \pm 14.75$ & $134.33 \pm 10.09$ & 0.1368 \\
\hline Diastolic BP (mm Hg) & $79.64 \pm 7.28$ & $83.86 \pm 6.64$ & $0.0247 *$ \\
\hline Height (cm) & $156.92 \pm 7.79$ & $153.5 \pm 6.91$ & 0.0819 \\
\hline Weight (Kg) & $60.25 \pm 8.89$ & $63.5 \pm 11.09$ & 0.2254 \\
\hline BMI $\left(\mathrm{Kg} / \mathrm{m}^{2}\right)$ & $24.48 \pm 3.26$ & $26.87 \pm 3.88$ & $0.0142 *$ \\
\hline WOMAC (baseline) & $42.59 \pm 19.49$ & $48.77 \pm 18.17$ & 0.2166 \\
\hline
\end{tabular}

The baseline physical parameters of patients in the two groups are almost comparable. 
Table 2: Baseline hematological and biochemical parameters of patients

\begin{tabular}{|l|c|c|c|}
\hline Parameters & $\begin{array}{c}\text { Oxaceprol group(n=28) } \\
(\text { Mean } \pm \text { S.D) }\end{array}$ & $\begin{array}{c}\text { Diacerein group } \\
(\mathbf{n = 3 0})(\text { Mean } \pm \text { S.D) }\end{array}$ & $\begin{array}{c}\text { p-value } \\
\text { (Unpaired t-test) }\end{array}$ \\
\hline Haemoglobin $(\mathrm{g} \%)$ & $12.28 \pm 1.91$ & $12.3 \pm 1.5$ & 0.9647 \\
\hline TLC $($ per cmm) & $7935.71 \pm 1332$ & $8363.33 \pm 1821.42$ & 0.3147 \\
\hline ESR $(\mathrm{mm} / \mathrm{h})$ & $30.6 \pm 8.92$ & $32 \pm 8.71$ & 0.5479 \\
\hline RBC $(\mathrm{millilion} / \mathrm{cmm})$ & $4.35 \pm 0.49$ & $4.43 \pm 0.48$ & 0.5326 \\
\hline Platelets (thousand/cmm) & $174.82 \pm 64.41$ & $168.9 \pm 49.51$ & 0.6951 \\
\hline Random Blood Sugar $(\mathrm{mg} / \mathrm{dl})$ & $96.17 \pm 12.02$ & $99 \pm 17.03$ & 0.4706 \\
\hline Cholesterol $(\mathrm{mg} / \mathrm{dl})$ & $218.82 \pm 47.35$ & $221.1 \pm 36.54$ & 0.8375 \\
\hline S Triglyceride $(\mathrm{mg} / \mathrm{dl})$ & $168.71 \pm 54.93$ & $183.76 \pm 80.08$ & 0.1791 \\
\hline HDL $(\mathrm{mg} / \mathrm{dl})$ & $56.39 \pm 14.88$ & $53.9 \pm 9.29$ & 0.4445 \\
\hline S.BIL-Total $(\mathrm{mg} / \mathrm{dl})$ & $0.63 \pm 0.33$ & $0.51 \pm 0.22$ & 0.1067 \\
\hline SGOT $(\mathrm{IU})$ & $26.53 \pm 11.25$ & $26.06 \pm 8.36$ & 0.8567 \\
\hline SGPT $(\mathrm{IU})$ & $28.03 \pm 8.97$ & $28.4 \pm 8.54$ & 0.8727 \\
\hline S Urea $(\mathrm{mg} / \mathrm{dl})$ & $28.07 \pm 8.05$ & $27.53 \pm 7.63$ & 0.7941 \\
\hline S Creatinine $(\mathrm{mg} / \mathrm{dl})$ & $0.94 \pm 0.26$ & $0.99 \pm 022$ & 0.4314 \\
\hline S Uric acid $(\mathrm{mg} / \mathrm{dl})$ & $5.51 \pm 1.5$ & $5.61 \pm 1.55$ & 0.8040 \\
\hline
\end{tabular}

The baseline hematological and biochemical parameters of patients in the two groups were comparable.

Table 3: Hematological and biochemical parameters of patients at the end of study

\begin{tabular}{|l|c|c|c|}
\hline Parameters & $\begin{array}{c}\text { Oxaceprol group }(\mathbf{n}=\mathbf{2 8}) \\
(\text { Mean } \pm \text { S.D) }\end{array}$ & $\begin{array}{c}\text { Diacerein group }(\mathbf{n}=30) \\
(\text { Mean } \pm \text { S.D })\end{array}$ & $\begin{array}{c}\text { p-value } \\
\text { (Unpaired t-test) }\end{array}$ \\
\hline Haemoglobin $(\mathrm{g} \%)$ & $12.26 \pm 1.64$ & $12.27 \pm 1.25$ & 0.9792 \\
\hline TLC $($ per cmm) & $7864.28 \pm 1044.63$ & $8356.66 \pm 1559.10$ & 0.1663 \\
\hline ESR $(\mathrm{mm} / \mathrm{h})$ & $29.53 \pm 7.47$ & $30.86 \pm 6.84$ & 0.4820 \\
\hline RBC $(\mathrm{millilion} / \mathrm{cmm})$ & $4.33 \pm 0.50$ & $4.36 \pm 0.46$ & 0.8128 \\
\hline Platelets (thousand/cmm) & $183.21 \pm 63.11$ & $159.9 \pm 40.97$ & 0.0986 \\
\hline Random Blood Sugar $(\mathrm{mg} / \mathrm{dl})$ & $99.32 \pm 12.85$ & $96.66 \pm 13.09$ & 0.4386 \\
\hline Cholesterol $(\mathrm{mg} / \mathrm{dl})$ & $230.14 \pm 49.89$ & $220.03 \pm 39.00$ & 0.3918 \\
\hline S Triglyceride $(\mathrm{mg} / \mathrm{dl})$ & $167.96 \pm 71.43$ & $183.03 \pm 75.25$ & 0.4381 \\
\hline HDL $(\mathrm{mg} / \mathrm{dl})$ & $54.71 \pm 6.51$ & $54.5 \pm 8.01$ & 0.9135 \\
\hline S.BIL-Total $(\mathrm{mg} / \mathrm{dl})$ & $0.57 \pm 0.20$ & $0.52 \pm 0.16$ & 0.2960 \\
\hline SGOT $(\mathrm{IU})$ & $26.57 \pm 7.09$ & $27.5 \pm 11.23$ & 0.7098 \\
\hline SGPT $(\mathrm{IU})$ & $30.03 \pm 7.79$ & $29.7 \pm 9.03$ & 0.8825 \\
\hline S Urea $(\mathrm{mg} / \mathrm{dl})$ & $26.96 \pm 5.50$ & $25.8 \pm 5.61$ & 0.4303 \\
\hline S Creatinine $(\mathrm{mg} / \mathrm{dl})$ & $0.91 \pm 0.20$ & $0.96 \pm 0.20$ & 0.3455 \\
\hline S Uric acid $(\mathrm{mg} / \mathrm{dl})$ & $5.34 \pm 1.34$ & $5.53 \pm 1.37$ & 0.5959 \\
\hline
\end{tabular}

The hematological and biochemical parameters of Patients in the two groups at the end of study were also comparable.

Table 4: Improvement in WOMAC Score at three months

\begin{tabular}{|c|c|c|c|}
\hline & $\begin{array}{c}\text { WOMAC-1 (baseline) } \\
\text { Mean } \pm \text { S.D. }\end{array}$ & $\begin{array}{c}\text { WOMAC }-2 \text { (at 3 months) } \\
\text { Mean } \pm \text { S.D. }\end{array}$ & $\begin{array}{c}\text { p-value } \\
\text { (Paired t-test) }\end{array}$ \\
\hline Oxaceprol & $42.59 \pm 19.49$ & $26.58 \pm 16.83$ & $0.00001 * * *$ \\
\hline Diacerein & $48.77 \pm 18.17$ & $29.40 \pm 19.94$ & $0.00001 * * *$ \\
\hline
\end{tabular}

$* * * \mathrm{p}$ value $<0.001$. On intragroup comparison the effectiveness of both the drugs was highly significant. 


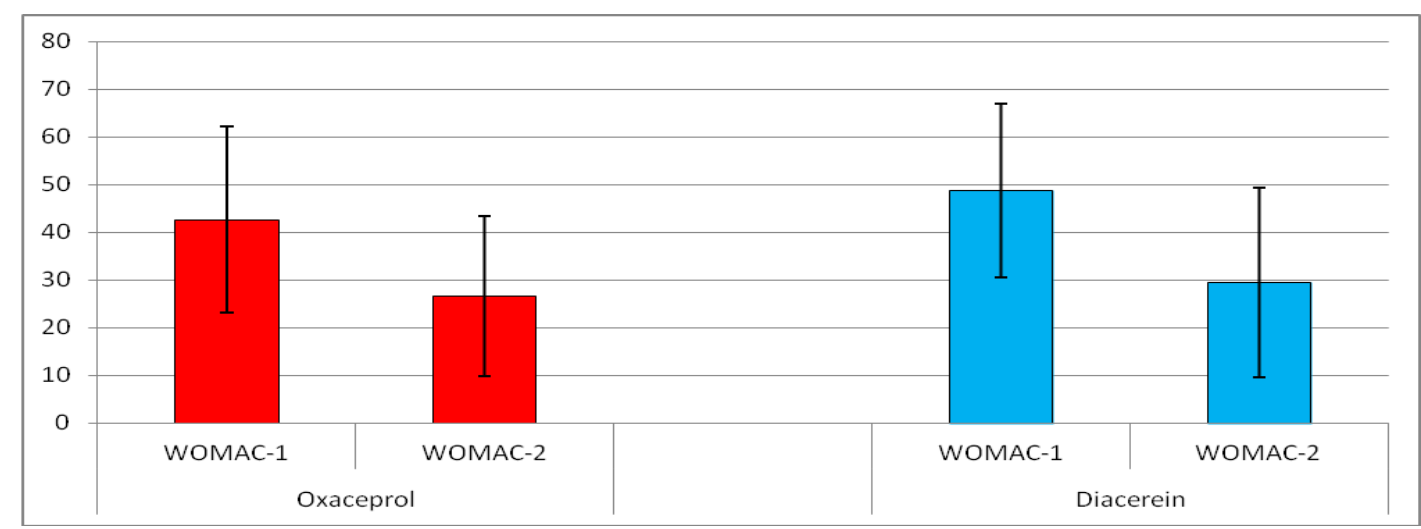

Fig. 1: Intragroup comparison of efficacy

Table 5: Oxaceprol group-Pre and post treatment comparison of hematological and biochemical parameters of patients $(n=28)$

\begin{tabular}{|l|c|c|c|}
\hline Parameters & $\begin{array}{c}\text { Pre treatment } \\
(\text { Mean } \pm \text { S.D })\end{array}$ & $\begin{array}{c}\text { Post treatment } \\
(\text { Mean } \pm \text { S.D) }\end{array}$ & $\begin{array}{c}\text { p-value } \\
\text { paired test }\end{array}$ \\
\hline Haemoglobin $(\mathrm{g} \%)$ & $12.28 \pm 1.91$ & $12.26 \pm 1.64$ & 0.41091 \\
\hline TLC $($ per cmm) & $7935.71 \pm 1332$ & $7864.28 \pm 1044.63$ & 0.37519 \\
\hline ESR $(\mathrm{mm} / \mathrm{h})$ & $30.6 \pm 8.92$ & $29.53 \pm 7.47$ & 0.20375 \\
\hline RBC $(\mathrm{millilion} / \mathrm{cmm})$ & $4.35 \pm 0.49$ & $4.33 \pm 0.50$ & 0.36174 \\
\hline Platelets (thousand/ cmm) & $174.82 \pm 64.41$ & $183.21 \pm 63.11$ & 0.14526 \\
\hline Random blood sugar $(\mathrm{mg} / \mathrm{dl})$ & $96.17 \pm 12.02$ & $99.32 \pm 12.85$ & $0.01625 *$ \\
\hline Cholesterol $(\mathrm{mg} / \mathrm{dl})$ & $218.82 \pm 47.35$ & $230.14 \pm 49.89$ & 0.06306 \\
\hline S Triglyceride $(\mathrm{mg} / \mathrm{dl})$ & $168.71 \pm 54.93$ & $167.96 \pm 71.43$ & 0.46959 \\
\hline HDL $(\mathrm{mg} / \mathrm{dl})$ & $56.39 \pm 14.88$ & $54.71 \pm 6.51$ & 0.26654 \\
\hline S.BIL-Total $(\mathrm{mg} / \mathrm{dl})$ & $0.63 \pm 0.33$ & $0.57 \pm 0.20$ & 0.05204 \\
\hline SGOT $(\mathrm{IU} / \mathrm{L})$ & $26.53 \pm 11.25$ & $26.57 \pm 7.09$ & 0.49102 \\
\hline SGPT $(\mathrm{IU} / \mathrm{L})$ & $28.03 \pm 8.97$ & $30.03 \pm 7.79$ & 0.09012 \\
\hline S Urea $(\mathrm{mg} / \mathrm{dl})$ & $28.07 \pm 8.05$ & $26.96 \pm 5.50$ & 0.22969 \\
\hline S Creatinine $(\mathrm{mg} / \mathrm{dl})$ & $0.94 \pm 0.26$ & $0.91 \pm 0.20$ & 0.24238 \\
\hline S Uric acid $(\mathrm{mg} / \mathrm{dl})$ & $5.51 \pm 1.5$ & $5.34 \pm 1.34$ & 0.18214 \\
\hline
\end{tabular}

${ }^{*} \mathrm{p}$ value $<0.05$. statistically significant but clinically not significant.

Table 6: Diacerein group- Pre and post treatment comparison of hematological and biochemical parameters of patients $(\mathbf{n}=30)$

\begin{tabular}{|l|c|c|c|}
\hline Parameters & $\begin{array}{c}\text { Pre treatment } \\
(\text { Mean } \pm \text { S.D) }\end{array}$ & $\begin{array}{c}\text { Post treatment } \\
(\text { Mean } \pm \text { S.D) }\end{array}$ & $\begin{array}{c}\text { p-value } \\
\text { (Paired t-test) }\end{array}$ \\
\hline Haemoglobin $(\mathrm{g} \%)$ & $12.3 \pm 1.5$ & $12.27 \pm 1.25$ & 0.37357 \\
\hline TLC $($ per cmm) & $8363.33 \pm 1821.42$ & $8356.66 \pm 1559.10$ & 0.49027 \\
\hline ESR $(\mathrm{mm} / \mathrm{h})$ & $32 \pm 8.71$ & $30.86 \pm 6.84$ & 0.12857 \\
\hline RBC $(\mathrm{millilion} / \mathrm{cmm})$ & $4.43 \pm 0.48$ & $4.36 \pm 0.46$ & $0.01692^{*}$ \\
\hline Platelets $($ thousand/ cmm) & $168.9 \pm 49.51$ & $159.9 \pm 40.97$ & $0.03205^{*}$ \\
\hline Blood Sugar Random $(\mathrm{mg} / \mathrm{dl})$ & $99 \pm 17.03$ & $96.66 \pm 13.09$ & 0.18015 \\
\hline Cholesterol $(\mathrm{mg} / \mathrm{dl})$ & $221.1 \pm 36.54$ & $220.03 \pm 39.00$ & 0.39854 \\
\hline S Triglyceride $(\mathrm{mg} / \mathrm{dl})$ & $183.76 \pm 80.08$ & $183.03 \pm 75.25$ & 0.45992 \\
\hline HDL $(\mathrm{mg} / \mathrm{dl})$ & $53.9 \pm 9.29$ & $54.5 \pm 8.01$ & 0.291575 \\
\hline S.BIL-Total $(\mathrm{mg} / \mathrm{dl})$ & $0.51 \pm 0.22$ & $0.52 \pm 0.16$ & 0.43578 \\
\hline SGOT $(\mathrm{IU} / \mathrm{L})$ & $26.06 \pm 8.36$ & $27.5 \pm 11.23$ & 0.15770 \\
\hline SGPT $(\mathrm{IU} / \mathrm{L})$ & $28.4 \pm 8.54$ & $29.7 \pm 9.03$ & 0.15260 \\
\hline S Urea $(\mathrm{mg} / \mathrm{dl})$ & $27.53 \pm 7.63$ & $25.8 \pm 5.61$ & 0.06666 \\
\hline S Creatinine $(\mathrm{mg} / \mathrm{dl})$ & $0.99 \pm 022$ & $0.96 \pm 0.20$ & 0.17693 \\
\hline S Uric acid $(\mathrm{mg} / \mathrm{dl})$ & $5.61 \pm 1.55$ & $5.53 \pm 1.37$ & 0.31709 \\
\hline
\end{tabular}

*p value $<0.05$; statistically significant but clinically not significant. 


\section{Discussion}

Efficacy Assessment: In our study, both the drugsoxaceprol and diacerein, have shown statistically highly significant but comparable improvement. In the study of Kruger et al, oxaceprol has shown clinically relevant improvement even though statistical significance was not met. ${ }^{4}$ In Shah $\mathbf{J}$ et al study the diacerein and oxaceprol have shown significant improvement on the VAS and the Lequesne scales. ${ }^{11}$

Safety Assessment: No adverse effect was reported by any subject and the hematological and biochemical parameters were also within normal range over a period of 3 months of observation. Therefore, both drugs were found to be safe for use in patients of OA knee.

\section{Limitations}

Short period of follow up and small sample size, due to wide exclusion criteria, were the two constrains of the study. Therefore long term studies on larger population are required to substantiate the result.

\section{Conclusion}

Both the drugs i.e. oxaceprol and diacerein, were found to be highly effective and safe in the treatment of OA knee grades I \& II. The drugs were also found to be comparable in efficacy and safety.

\section{Financial Support and Sponsorship: Nil.}

Conflicts of Interest: There was no conflict of interest.

\section{Acknowledgement}

The authors are thankful to the departments of Biochemistry and Pathology and hospital administration for their co-operation in the study.

\section{References}

1. Mahajan A, Verma S, Tandon V. Osteoarthritis. J Assoc Physician India. 2005;53:634-41.

2. National Institute for Health and Care Excellence. Osteoarthritis; Care and management in adults; Clinical guideline G177: Methods, evidence and recommendations. UK: National Clinical Guideline Centre; 2014.p15.

3. Litwic A, Edwards M, Dennison E, Cooper C. Epidemiology and Burden of Osteoarthritis. Br Med Bull. 2013;105:185-99.

4. Krüger K, Klasser M, Mössinger J, Becker U. Oxaceprol - a randomized placebo- controlled clinical study in osteoarthritis with a non-conventional non- steroidal antiinflammatory drug. Clinical and Experimental Rheumatology. 2007;25:29-34.
5. Herrmann G, Steeger D, Klasser M, Wirbitzky J, Fürst M, Venbrocks R, et al. Oxaceprol is a well tolerated therapy for osteoarthritis with efficacy equivalent to diclofenac. Clin Rheumatol. 2000;19:99-104.

6. Veihelmann A, Hofbauer A, Refior HJ, Messmer K. Oxaceprol, an atypical inhibitor of inflammation, reduces leukocyte adherence in mouse antigen induced arthritis. Acta Orthop Scand. 2001;72:293-8.

7. Pelletier JP, Yaron M, Haraoui B, Cohen P, Nahir MA, Choquette D, et al. Efficacy and safety of diacerein in osteoarthritis of the knee: a double blind, placebo controlled trial. Arthritis Rheum. 2000;43:2339-48.

8. ACR Diagnostic guidelineshttps://www.hopkinsarthritis.org/physician corner/education/arthritis-education-diagnosticguidelines/\#class_knee

9. Arden N, Javaid K, Cooper C. Epidemiology of Osteoarthritis. In: Arden N, Blanco FJ, Cooper C, Guermazi A, Hayashi D, Hunter D, et al. editors. Atlas of Osteoarthritis. London: Springer Healthcare; 2014, p.21.

10. WOMAC Arthritic Index. Available at: https://www.physio-pedia.com /WOMAC_ Osteoarthritis_Index \# Method_of_Use (accessed on $1^{\text {st }}$ Jan 2016)

11. Shah J, Mirza N, Patel V. A Comparative Study For Safety And Efficacy Of Oxaceprol And Diacerein Osteoarthritis Of Knee Joints; Pharma Tutor. 2014;2(6):108-114. 